\title{
Approaches to estimating the transfer of radionuclides to Arctic biota
}

\author{
N.A. Beresford ${ }^{1}$, S.M. Wright ${ }^{1}$, C.L. Barnett ${ }^{1}$, V. Golikov ${ }^{2}$, V. Shutov ${ }^{2}$ \\ and O. Kravtsova ${ }^{2}$ \\ ${ }^{1}$ Centre for Ecology \& Hydrology, Lancaster Environment Centre, Library Avenue, Bailrigg, \\ Lancaster LA1 4AP, UK, e-mail: nab@ceh.ac.uk \\ ${ }^{2}$ Institute for Radiation Hygiene, Mira Str. 8, 197101 St. Petersburg, Russia
}

\begin{abstract}
We review collated data and available models for estimating the transfer of radionuclides to terrestrial biota within the European Arctic. The most abundant data are for radiocaesium and radiostrontium although many data for natural radionuclides are available. For some radionuclides no data are available for describing transfer to Arctic biota. Allometric-kinetic models have been used to estimate transfer for radionuclide-biota combinations. Predicted values were in good agreement with observed data for some radionuclides although less so for others. There are no bespoke models to enable the dynamic prediction of radionuclide transfer to Arctic biota. A human Arctic foodchain model has been adapted to estimate ${ }^{137} \mathrm{Cs}$ and ${ }^{90} \mathrm{Sr}$ transfer to some Arctic biota. There are many factors of Arctic ecosystems which may influence radionuclide behaviour including short growing seasons, prolonged soil freezing, and effects of low temperatures on biological rates. If exposure to ionising radiation in Arctic ecosystems is to be robustly predicted such factors must be fully understood and incorporated into models.
\end{abstract}

\section{INTRODUCTION}

Low temperatures, extreme seasonal variations in light and lack of nutrients are some of the physical and chemical characteristics which cause environmental stress to organisms in the Arctic, limiting biodiversity and making organisms potentially more vulnerable to contaminants [1]. There is increasing concern over potential nuclear contamination of the Arctic due to the wide range of sources and the current economic situation within the former Soviet Union [1]. Within the European Arctic these include: the Novaya Zemlya weapons test site; 17 'peaceful' nuclear civil engineering explosion sites within or close to the Arctic Circle; the Kola and Bilibino power plants; and nuclear powered vessels and spent fuel of the Russian civilian and military fleets. In the Komi Autonomous Republic, there are also small areas of high natural radiation in tundra ecosystems.

There are a number of on-going and recently completed national and international programmes to establish approaches to estimate radiation exposure of wild species and predict subsequent effects [2]. An essential step in being able to predict doses to biota is the estimation of radionuclide transfer to biota to allow the quantification of internal dose. In this paper we describe the derivation of radionuclide transfer parameters for European Arctic terrestrial biota which are an element of the impact assessment framework for the European Arctic of Brown et al. [3] (comparable work for Arctic marine species has been described [4]). A range of anthropogenic and natural radionuclides appropriate to assessments in the European Arctic and representing a range of environmental mobilities and biological uptake rates are considered. These are radioisotopes of Cs, Sr, I, Tc, Pu, Am, U, Ra, Th and Po. The framework also considers ${ }^{14} \mathrm{C}$ and ${ }^{3} \mathrm{H}$, the specific activity approaches adapted to derive transfer parameters for these radionuclides are described elsewhere [5].

A problem in the development of an environmental protection framework is the diversity and number of flora and fauna species. In response to this, the use of reference organisms has been suggested to represent flora and fauna for which doses and potential effects are to be predicted [6]. Reference organisms for European Arctic ecosystems were selected on the basis of radiosensitivity, likely internal and/or external exposure, ecological niche, distribution and amenability for research 
and monitoring [7]. The selected terrestrial reference organisms are presented in Table 1 together with suggested representative (typical and ubiquitous) species. These organisms are a potential list for use in assessment of the impact of ionising radiation in the Arctic; they may not all be applicable to any given evaluation but are sufficiently broad ranging to enable assessments to be conducted throughout different terrestrial Arctic ecosystems.

\section{REVIEW OF SOIL-BIOTA TRANSFER VALUES}

More than 300 publications were reviewed; species selected as representative of Arctic reference organisms were targeted within the literature review. However, the review was not restricted to studies conducted within the European Arctic because of the paucity of data. Data sources comprised: English language refereed publications and conference proceedings and citied works within these; data from studies conducted in areas of elevated natural radionuclides within the Komi Autonomous Republic (Institute for Radiation Hygiene, IRH); and data on the transfer of a range of radionuclides to wildlife species from throughout European Russia (with an emphasis on Arctic regions and post-Chernobyl studies) (IRH). A considerable number of data were rejected from the review as the level of detail within the original publications was insufficient to enable its use with confidence.

Table 1. Selected terrestrial reference organisms and representative species for the European Arctic.

\begin{tabular}{ll}
\hline Reference organism & Representative species \\
\hline Soil micro-organism ${ }^{1}$ & Not applicable \\
Lichens \& Bryophytes & Cladonia spp. \\
Gymnosperm & Juniperus spp., Larix dahurica, Picea obovata \\
Monocotyledon & Carex spp., Luzula spp., Festuca spp. \\
Dicotyledon & Vaccinium spp. \\
Soil invertebrate ${ }^{1}$ & Collembola \& mites \\
Herbivorous mammal & 'Lemmings and voles' (e.g. Lemmus spp. and Clethrionomys spp...) ${ }^{2}$ Reindeer (Rangifer \\
& tarandus) $^{3}$ \\
Carnivorous mammal & 'Foxes' (Vulpes vulpes \& Alopex lagopus) \\
Herbivorous bird and egg & Lagopus spp. \\
${ }^{1}$ Transfer to these organism not considered as it was assumed that external doses will dominate due to their small size; \\
${ }^{2}$ Common throughout Low- and Sub- Arctic; ${ }^{3}$ Occurs from sub- to high- Arctic.
\end{tabular}

\subsection{Data manipulation}

All collated transfer parameters were transformed to concentration ratio (CR) values defined here as the ratio of the radionuclide activity concentration in an organism $\left(\mathrm{Bq} \mathrm{kg^{-1 }} F W\right.$ or DM) to the radionuclide activity concentration in soil $\left(\mathrm{Bq} \mathrm{kg}{ }^{-1} \mathrm{DM}\right)$. Where original references reported transfer relative to the radionuclide activity per $\mathrm{m}^{2}$ of soil, a bulk density for Arctic soils of $0.78 \mathrm{~g} \mathrm{DM} \mathrm{cm}^{-3}$ and a sampling depth of $10 \mathrm{~cm}$ have been assumed to derived CR values. All transfer data for plant species were converted to a dry matter basis whilst all animal data has been transformed to fresh weight. Strontium-90 and ${ }^{137} \mathrm{Cs}$ data collected during the period of weapons fallout (pre-1970) or the year of the Chernobyl accident were not used to avoid the effects of vegetation surface contamination.

For the purpose of estimating internal doses of wild animals, we need transfer parameters to enable the prediction of whole body activity concentrations. However, much of the available data is reported for specific organs. Where information on the relative distribution of a given radionuclide within animals was available, whole body activity concentrations were generated by assuming the proportion of total live-weight and radionuclide contributed by the organ for which transfer was reported. For instance, the majority of the available data for ${ }^{90} \mathrm{Sr}$ is for bone. It was assumed that $97 \%$ of the body ${ }^{90} \mathrm{Sr}$ was present in bone (analyses of available collated data) and that bone contributed $10 \%$ of the live-weight of mammalian species to generate whole-body ${ }^{90} \mathrm{Sr}$ activity concentrations. As radiocaesium is known to be approximately homogenously distributed throughout body tissues, reported transfer values to muscle were considered to be representative of whole-body. Collated data for plants were reported for a range of plant parts (e.g. data for Vaccinium spp. were dominated by berries); no differentiation between plant parts was taken into account in the derivation of transfer values. 
For plant reference organisms all data summarised in subsequent tables are from the Arctic or at unspecified locations in countries with Arctic territories. Some sources present individual data values whilst others present mean transfer estimates; in the calculation of arithmetic mean transfer values, previously reported mean estimates have been treated as single data values.

\subsection{Available data}

The majority of available Arctic specific soil-biota transfer data are for ${ }^{137} \mathrm{Cs}$ and ${ }^{90} \mathrm{Sr}$ from global fallout and, to a lesser extent, the Chernobyl accident, and natural radionuclides from the U-decay series (Table 2). Data for U-decay series were dominated by studies from within the European Arctic. For Cs, data were available for all representative species with the exception of Lagopus spp. egg. No Arctic specific data for the transfer of actinide elements from soil-biota were found during this review and few appropriate data are available for reference organism groups from studies conducted elsewhere [8]. The only CR values available for both ${ }^{241} \mathrm{Am}$ and $\mathrm{Pu}$ were for herbivorous mammal of $2.26 \times 10^{-3}$ and $1.01 \times 10^{-3}$ respectively. Data expressing the transfer of Tc or I from soil - reference organisms were not available. A summary of the available transfer values is presented in Table 3. Where there are sufficient data to comment variation in the available values is high (typically 2-3 orders of magnitude) with highly skewed distributions (predominantly log-normal). Some species dominate the available data for instance for the transfer of many radionuclides to herbivorous mammals the most numerous data are for reindeer (e.g. $>60 \%$ of Cs values and $>80 \%$ of Sr values).

Table 2. Number of available CR values found for each radionuclide - reference organism combination.

\begin{tabular}{|c|c|c|c|c|c|c|c|c|c|c|}
\hline $\begin{array}{l}\text { Reference organism } \\
\text { (Representative species) }\end{array}$ & Cs & Sr & $\mathbf{I}$ & Tc & $\mathbf{P u}$ & Am & $\mathbf{U}$ & $\mathbf{R a}$ & Th & Po \\
\hline Lichens+bryophytes $^{1}$ & 388 & 356 & - & - & - & - & 1 & 6 & 6 & 5 \\
\hline Gymnosperms & 22 & 13 & - & - & - & - & 11 & 4 & 2 & - \\
\hline Dicotyledons $^{2}$ & 457 & 63 & - & - & - & - & 10 & 7 & 6 & 4 \\
\hline Monocotyledons & 435 & 321 & - & - & - & - & - & 1 & - & 2 \\
\hline $\begin{array}{l}\text { Herbivorous mammal } \\
\text { (Microtus spp./Lemmus spp.) }\end{array}$ & 4 & - & - & - & - & - & 2 & 17 & 2 & - \\
\hline $\begin{array}{l}\text { Herbivorous mammal } \\
\text { (Rangifer tarrandus) }\end{array}$ & 845 & 365 & - & - & - & - & - & 16 & 6 & 42 \\
\hline Carnovorous mammal & 12 & 8 & - & - & - & - & 1 & 17 & 2 & 3 \\
\hline Herbivorous bird & 56 & $51^{3}$ & - & - & - & - & 4 & 31 & 4 & - \\
\hline
\end{tabular}

All data are for: ${ }^{1}$ Cladonia spp.; ${ }^{2}$ Vaccinum spp.; ${ }^{3}$ Lagopus spp..

\section{ADDRESSING DATA GAPS}

There are few or no data describing transfer for many radionuclide-Arctic biota combinations. Previously we have reviewed the merits of various approaches which have been suggested for deriving transfer values for use in environmental assessments [8]. Here we will restrict discussion to the suggestion of approaches for use in terrestrial Arctic ecosystems.

There was a lack of Arctic specific transfer values for I, Tc, Am, U, Th and Pu for monocotyledons, however, values for the transfer of these radionuclides to grass are available [9]. Where comparison is possible the Arctic transfer values summarised for monocotyledons (Table 3) are generally in the range of values presented for grass [9]. No data were available describing the transfer of radionuclides to the eggs of wild herbivorous bird species. For Cs and U, CR values for Lagopus spp. egg were derived by comparison of the transfer of Cs from diet to meat and eggs of domestic hens [9] with soil-muscle CR values collated for wild herbivorous species (Table 3). The resultant CR estimates are $6.4 \times 10^{-2}$ and $2.0 \times 10^{-3}$ for $\mathrm{Cs}$ and $\mathrm{U}$ respectively. No data were available describing the transfer of ${ }^{210} \mathrm{Po}$ from soil-carnivorous mammals. Values are available for the transfer from reindeer to wolf muscle [10], assuming a distribution of ${ }^{210} \mathrm{Po}$ in carnivorous mammals consistent with that in herbivores this was used to adapt the herbivorous mammal CR value to a 
soil-carnivorous mammal CR of 1.7.

Table 3. Summarised CR values for Arctic reference organisms and representative species.

\begin{tabular}{|c|c|c|c|c|c|c|}
\hline \multirow{2}{*}{$\begin{array}{l}\text { Reference organism } \\
\text { /representative } \\
\text { species }\end{array}$} & \multicolumn{6}{|c|}{$\begin{array}{c}\text { Bq kg }^{-1} \text { organism: Bq kg }{ }^{-1} \text { soil (dry weight) } \\
\text { mean / range }\end{array}$} \\
\hline & Cs & ${ }^{90} \mathrm{Sr}$ & ${ }^{210} \mathrm{Po}$ & ${ }^{226} \mathbf{R a}$ & Th & $\mathbf{U}$ \\
\hline Lichen & $\begin{array}{c}7.54 \\
0.13-22.8\end{array}$ & $\begin{array}{c}6.46 \\
0.2242 .6\end{array}$ & $\begin{array}{c}0.28 \\
0.01-0.88\end{array}$ & $\begin{array}{c}0.83 \\
0.48-1.39\end{array}$ & $\begin{array}{c}0.27 \\
0.16-0.62\end{array}$ & 0.20 \\
\hline Gymnosperm & $\begin{array}{c}0.95 \\
0.04-5.54\end{array}$ & $\begin{array}{c}1.33 \\
0.11-3.79 \\
\end{array}$ & - & $\begin{array}{c}2.13 \\
(0.01-72.6) \mathrm{E}-1 \\
\end{array}$ & $\begin{array}{c}0.22 \\
0.17-0.28 \\
\end{array}$ & $\begin{array}{c}0.29 \\
(0.02-116) \mathrm{E}-2 \\
\end{array}$ \\
\hline Juniperus spp. & $\begin{array}{c}0.51 \\
0.28-1.20\end{array}$ & - & - & $\begin{array}{c}4.26 \\
1.25-7.26\end{array}$ & - & $\begin{array}{c}0.30 \\
0.05-0.55\end{array}$ \\
\hline Larix /Picea spp. & $\begin{array}{c}0.20 \\
0.04-0.51\end{array}$ & - & $3.25 \mathrm{E}-3$ & $5.25 \mathrm{E}-3$ & - & $1.75 \mathrm{E}-4$ \\
\hline Vaccinium spp. & $\begin{array}{c}2.86 \\
0.70-176\end{array}$ & $\begin{array}{c}0.58 \\
0.03-6.04\end{array}$ & $\begin{array}{c}1.23 \\
0.19-3.17\end{array}$ & $\begin{array}{c}3.56 \\
(0.06-76.4) \mathrm{E}-1\end{array}$ & $\begin{array}{c}0.16 \\
0.02-0.24\end{array}$ & $\begin{array}{c}0.32 \\
(0.02-75.0) \mathrm{E}-2\end{array}$ \\
\hline Salix spp. & $\begin{array}{c}0.51 \\
0.007-0.18\end{array}$ & $\begin{array}{c}3.35 \\
0.18-10.8\end{array}$ & $8.50 \mathrm{E}-3$ & $1.25 \mathrm{E}-3$ & - & $1.00 \mathrm{E}-4$ \\
\hline Monocotyledon & $\begin{array}{c}0.98 \\
0.06-18.4\end{array}$ & $\begin{array}{c}0.35 \\
0.09-1.47\end{array}$ & $\begin{array}{c}0.44 \\
0.32-0.56\end{array}$ & $5.66 \mathrm{E}-3$ & - & - \\
\hline Herbivorous mammal & $\begin{array}{c}7.01 \\
0.01-76.1 \\
\end{array}$ & $\begin{array}{c}2.89 \\
0.03-79.6 \\
\end{array}$ & $\begin{array}{c}4.17 \\
0.40-14.3 \\
\end{array}$ & $\begin{array}{c}4.77 \mathrm{E}-2 \\
(0.21-19.5) \mathrm{E}-2 \\
\end{array}$ & $\begin{array}{c}0.28 \\
(0.21-46.6) \mathrm{E}-2 \\
\end{array}$ & $\begin{array}{c}1.80 \mathrm{E}-3 \\
(0.12-2.84) \mathrm{E}-3\end{array}$ \\
\hline Reindeer & $\begin{array}{c}9.91 \\
0.07-45.1\end{array}$ & $\begin{array}{c}3.48 \\
0.03-84.2\end{array}$ & $\begin{array}{c}4.17 \\
0.40-14.3\end{array}$ & $\begin{array}{c}6.07 \mathrm{E}-2 \\
(0.31-15.9) \mathrm{E}-2\end{array}$ & $\begin{array}{c}0.37 \\
0.23-0.47\end{array}$ & - \\
\hline Lemmings \& Voles & $\begin{array}{c}3.49 \\
1.69-4.43\end{array}$ & & - & $\begin{array}{c}6.91 \mathrm{E}-2 \\
0.01-0.20\end{array}$ & $\begin{array}{c}7.74 \mathrm{E}-3 \\
(0.21-1.33) \mathrm{E}-2\end{array}$ & $\begin{array}{c}2.60 \mathrm{E}-3 \\
(2.40-2.80) \mathrm{E}-3\end{array}$ \\
\hline Carnivorous mammal & $\begin{array}{c}2.76 \\
0.10-12.9 \\
\end{array}$ & $\begin{array}{c}0.72 \\
0.12-1.86 \\
\end{array}$ & - & $\begin{array}{c}3.53 \mathrm{E}-2 \\
(0.43-9.56) \mathrm{E}-2 \\
\end{array}$ & $\begin{array}{c}\text { 5.52E-3 } \\
(0.1-1.0) \mathrm{E}-2\end{array}$ & $7.09 \mathrm{E}-4$ \\
\hline Fox & $\begin{array}{c}0.65 \\
0.10-1.68 \\
\end{array}$ & - & - & $4.00 \mathrm{E}-3$ & - & - \\
\hline Herbivorous bird & $\begin{array}{c}0.89 \\
0.02-9.05\end{array}$ & - & - & $\begin{array}{c}3.38 \mathrm{E}-2 \\
(0.21-19.5) \mathrm{E}-2\end{array}$ & $\begin{array}{c}3.89 \mathrm{E}-4 \\
(3.08-5.44) \mathrm{E}-4\end{array}$ & $\begin{array}{c}4.98 \mathrm{E}-4 \\
(4.05-6.76) \mathrm{E}-4\end{array}$ \\
\hline Lagopus spp. & $\begin{array}{c}0.76 \\
0.02-3.22\end{array}$ & $\begin{array}{c}3.52 \mathrm{E}-2 \\
0.002- \\
0.22 \\
\end{array}$ & - & $\begin{array}{c}2.53 \mathrm{E}-2 \\
(0.91-5.07) \mathrm{E}-2\end{array}$ & $3.52 \mathrm{E}-4$ & 4.05E-4 \\
\hline
\end{tabular}

${ }^{\mathrm{C}} \mathrm{CR}$ values calculated on basis of DM activity concentrations in plants and of $\mathrm{FW}$ activity concentrations in animals.

\subsection{Allometry}

Allometry, or biological-scaling, is the consideration of the effect of size on biological variables. The dependence of a biological variable $\mathrm{Y}$ on a body mass $\mathrm{M}$ is typically characterised by allometric equations of the form $\mathrm{Y}=\mathrm{aM}^{\mathrm{b}}$. Allometric relationships for the biological half-life and dietary transfer coefficient for some radionuclides have been derived [8]. A kinetic-allometric approach has been suggested [11] which uses allometric relationships including the long component of radionuclide biological half-life, food intake, inhalation rate, water intake and life expectancy for use in the modelling of internal exposure of wild animals. We used this approach, in combination with soil-plant transfer values (taken from Table 3 or [9]) for dietary components, to estimate soil-biota transfer values for Arctic reference organisms [8]. Soil ingestion rates of 10\% DM intake for herbivores and 6\% for fox were assumed (see [8] for further details). Daily DM ingestion rates were predicted using the allometric relationships for carnivorous mammals (fox), rodents (vole) and galliformes (Lagopus spp.) [12]; intakes of grass and lichen by reindeer were taken from [13]. Voles were assumed to eat grass, Lagopus spp. to eat Vaccinium spp., and foxes to consume the soft tissues of voles. Estimates were made for animals of average age and these are presented in Table 4 (NB. in [8] transfer values were presented as the activity concentration in biota relative to the activity per metre squared, these have been re-calculated as CR values in Table 4). Generally predicted transfer values are comparable with the range of observed data for the representative species (or at least reference organism) with the exception of predictions for Ra which are high compared with observed data. 
Table 4. CR values (fresh weight) for representative species predicted using a kinetic-allometric approach.

\begin{tabular}{lccccccccc}
\hline $\begin{array}{l}\text { Representative } \\
\text { species }\end{array}$ & Cs & Sr & Tc & Am & Pu & I & U & Th & Ra \\
\hline Vole & 1.9 & 5.8 & 2.9 & $2.3 \times 10^{-4}$ & $2.1 \times 10^{-4}$ & $3.6 \times 10^{-1}$ & $4.2 \times 10^{-3}$ & $4.2 \times 10^{-4}$ & 1.2 \\
Reindeer & 7.9 & $2.8 \times 10^{1}$ & - & - & - & - & $9.1 \times 10^{-3}$ & $2.2 \times 10^{-3}$ & 3.4 \\
Fox & 7.9 & $1.2 \times 10^{1}$ & $6.0 \times 10^{-1}$ & $1.7 \times 10^{-4}$ & $1.7 \times 10^{-4}$ & 1.7 & $1.6 \times 10^{-3}$ & $4.4 \times 10^{-4}$ & 2.3 \\
Lagopus spp. & 2.1 & 3.9 & - & - & - & - & $6.2 \times 10^{-3}$ & $1.4 \times 10^{-3}$ & $1.0 \times 10^{1}$ \\
\hline
\end{tabular}

\subsection{Adaptation of a human foodchain model}

There are no bespoke models available for predicting temporal changes in the transfer of radionuclides deposited in Arctic terrestrial ecosystems to biota. However a limited number of models applied within the Arctic to estimate exposure of humans consider some wild species (e.g. reindeer). The most comprehensive of these is ECOMARC [13]. This dynamic compartment model for $\mathrm{Sr}$ and $\mathrm{Cs}$ is an adaptation of ECOSYS-87 which was developed to assess the radiological consequences for agricultural ecosystems in temperate latitudes following releases (of a range) of radionuclides into the environment [14]. Where possible, Arctic specific model parameters are used in ECOMARC including: months and amounts of snowfall; time of snow melt; seasonally varying dietary intake of reindeer; transfer coefficients and biological half-lives for reindeer. We have further developed ECOMARC to allow simulations of activity concentrations in an herbivorous (reindeer) - carnivorous mammal (nominally a wolf) foodchain. Caesium-137 and ${ }^{90} \mathrm{Sr}$ activity concentrations in reindeer muscle predicted by ECOMARC have been used to predict the whole body ${ }^{137} \mathrm{Cs}$ and ${ }^{90} \mathrm{Sr}$ activity concentrations in wolves, hypothetically consuming reindeer as their sole dietary intake. Allometric relationships have been used to estimate the radionuclide biological half-life and dry-matter intake for wolves (Figure 1). Similar adaptations to ECOMARC using observed, or predicted, biological half-lives could be readily made for some other Arctic reference organism. ECOSYS-87, from which ECOMARC was derived, considers a wide range of radionuclides and the approach could be extended to these. ECOMARC could be adapted for other herbage types using CR values in Table 3. However, appropriate radionuclide specific parameters (e.g. weathering half-lives, deposition velocities) are unlikely to be available for these vegetation types in Arctic ecosystems.

\section{FACTORS INFLUENCING RADIONUCLIDE TRANSFER IN ARCTIC ECOSYSTEMS}

On the basis of the available data considered in this review it was generally not possible to comment on the transfer of radionuclides to biota within the Arctic compared to other areas. There are many factors of Arctic ecosystems which may influence radionuclide behaviour including short growing seasons, prolonged freezing of soil, and effects of low temperatures on biological rates. The influence of some of these have been documented: redistribution within the soil profile as a result of freezing $[15,16]$; reduction of soil ${ }^{14} \mathrm{CO}_{2}$ degassing rates as a consequence of freezing [17]; effects of temperature, metabolic rate and dietary intake on radionuclide transfer to animals [18-20]; reduced sorption rate in soils at lower temperature [21]; and reduced uptake of Cs by soil invertebrates at low temperatures [22]. If exposure to ionising radiation within Arctic terrestrial ecosystems is to be robustly predicted, such factors must be fully understood and properly incorporated into models.

\section{Acknowledgements}

This paper is based upon work performed under the EC $5^{\text {th }}$ Framework project EPIC (ICA2-CT-2000-10032). 


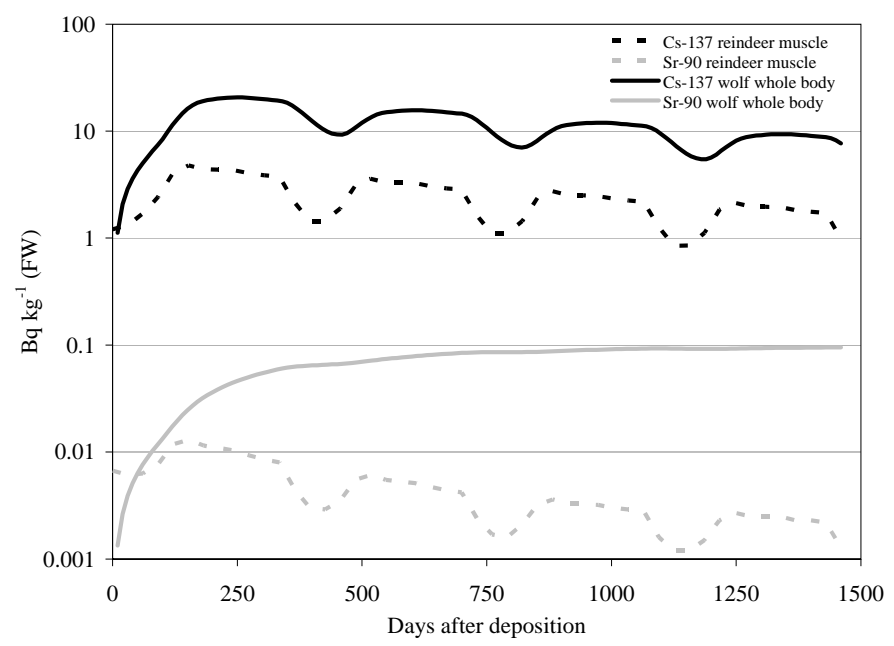

Figure 1. ECOMARC model prediction assuming a single deposition of $1 \mathrm{~Bq} \mathrm{~m}^{-2}$ of each of ${ }^{137} \mathrm{Cs}$ and ${ }^{90} \mathrm{Sr}$ (time $0=$ June).

\section{References}

[1] AMAP, Arctic Pollution Issues, (AMAP, Oslo, 1998).

[2] IAEA, Conference on the Protection of the Environment from the Effects of Ionizing Radiation, IAEA-CN-109 (IAEA, Stockholm, 2003).

[3] J. Brown, H. Thørring, A. Hosseini, (editors), The 'EPIC' impact assessment framework, FIGE-CT-2000-00102 (FASSET), (NRPA, Østerås, 2003).

[4] J. Brown, P. Børretzen, M. Dowdall, T. Sazykina, I Kryshev, Arctic, (in press).

[5] D. Galeriu, N.A. Beresford, A. Melintescu, R. Avila, N.M.J. Crout, in Conference on the Protection of the Environment from the Effects of Ionizing Radiation, IAEA-CN-109, (IAEA, Stockholm, 2003), p. 186.

[6] R.J. Pentreath, D.S. Woodhead, Sci. Tot. Environ., 277, 33 (2001).

[7] N.A. Beresford, S.M. Wright, T. Sazykina, (editors), Reference Arctic organisms, ICA2-CT-2000-10032, (CEH, Grange-over-Sands, 2001).

[8] N.A. Beresford, M.R. Broadley, B.J. Howard, C.L. Barnett, P.J. White, J. Rad. Prot., (in press).

[9] IAEA, Handbook of transfer parameter values for the prediction of radionuclide transfer in temperate environments, IAEA TECDOC 364, (IAEA, Vienna, 1994).

[10] P.A. Thomas, J.W. Sheard, S. Swanson, Hlth. Phys., 66, 666 (1994).

[11] K.A. Higley, S.L. Domotor, E.J. Antonio, J. Environ. Radioact., 66, 61 (2003).

[12] K.A. Nagy, Nutrition Abstracts and Reviews, Series B, 71, 21 (2001).

[13] V. Yu. Golikov, Operational models for calculation of internal and external doses in the Arctic, ERB IC 15-CT980201, (IRH, St. Petersburg, 2001).

[14] H. Müller, G. Pröhl, Hlth. Phys., 64, 232 (1993).

[15] A.P. Butler, S. Burne, H.S. Wheater, Hydro. Process., 10, 471 (1996).

[16] R.X. Saxena, N.J. Jarvis, L. Bergström, J. Hydrol., 162, 279 (1994).

[17] M.I. Sheppard, L.L. Ewing, J.L. Hawkins, J. Environ. Qual., 23, 461 (1994).

[18] F.W. Lengemann, Hlth Phys., 19, 785 (1970).

[19] F.W. Lengemann, R.A. Wentworth, Hlth. Phys., 36, 1267 (1979).

[20] N.A. Beresford, R.W. Mayes, C.L. Barnett, C.S. Lamb, Radioprotection colloques, 37, 373 (2002).

[21] K. Bunzl, W. Scimmack, Radiochimica Acta., 54, 97 (1991).

[22] M.P.M. Janssen, P. Glastra, J.F.M.M. Lembrechts, Arch. Environ. Contam. Toxicol., 31, 184 (1996). 